\title{
UTILIZAÇÃO DE POLIACRILATO NO TRATAMENTO DE MINÉRIOS DE FERRO*
}

Filipe Augusto Vasconcelos Guimarães ${ }^{1}$ Armando Corrêa de Araujo ${ }^{2}$ Imad Karkor ${ }^{3}$

\section{Resumo}

O presente artigo discute as interferências causadas pelo incremento gradual de umidade nos minérios produzidos atualmente, especialmente aqueles produzidos diretamente para carregamento. $O$ aumento de umidade representa um desafio constante no transporte e tratamento dos materiais produzidos, uma vez que a simplificação dos fluxogramas pode também significar uma importante parcela na redução dos custos, tema hoje primordial na sobrevivência de qualquer empreendimento de minério de ferro. A utilização de reagentes auxiliares para ajudar no tratamento e transporte desses materiais pode significar a diferença entre a manutenção ou o fechamento de uma mina.

Palavras-chave: Umidade; Transporte; Custo.

\begin{abstract}
USING OF POLYACRYLATES IN THE TREATMENT OF IRON ORE
Abstract

This article discusses some of the interferences caused by the gradual increase of moisture in the iron ore production nowadays, especially those produced directly for shipment. The increase of moisture represents a constant challenge in the transport and beneficiation of the produced materials, once the simplification of the flow sheet many times could mean also an important part in the cost reduction, nowadays, primordial theme for the survival of any iron ore business. The using of auxiliary reagents to help in the treatment and transport of those materials could mean the difference between keeping open and closing a mine.
\end{abstract}

Keywords: Moisture; Transport; Cost.

1 Engenheiro de Minas M.Sc., Leader of Beneficiation Team at ArcelorMittal's Research Center $\square$

2 Engenheiro de Minas, PhD., Head of Mining R\&D ArcelorMittal Minning.

3 Engenheiro de Materiais, Research Engineer at ArcelorMittal's Reseach Center 


\section{INTRODUÇÃO}

Com a redução do valor do minério de ferro no mercado internacional, mais do que nunca se faz necessária a utilização de formas diretas e baratas de produção do minério. No entanto, a utilização direta de alguns materiais pode significar empobrecimento do material a ser vendido e, principalmente, dificuldades no tratamento desses materiais, uma vez que, em sua maioria, são tratados à umidade natural, o que por si só já representa um grande desafio para o tratador de minérios. Minérios chamados de embarque direto, ou DSO (Direct Shipping Ore), representam uma grande parcela das grandes companhias, como Vale, BHP e Rio Tinto. São materiais lavrados que passam por processos simples de classificação e são vendidos (e embarcados) sem processos de concentração. No entanto, o tratamento e transporte desses materiais, principalmente nos países tropicais, tem apresentado problemas contanstes em relação à umidade.

A utilização de aditivos especiais tem se mostrado uma arma poderosa no combate ao excesso de umidade, principalmente no transporte, mas agora vem se mostrando potencialmente útil para o enriquecimento desses materiais com o objetivo de melhorar sua aceitabilidade no mercado internacional.

\subsection{Efeito da Umidade na Concentração a Umidade Natural}

A umidade em certos materiais pode trazer benefícios ou malefícios ao tratamento de minérios de ferro, dependendo de sua proporção ou do tipo de material submetido a altos ou baixos graus de umidade. Fatores intrínsecos podem contribuir para o alto grau de retenção de umidade, tais como o percentual de partículas finas e ultra-finas presentes no material, ou até mesmo a porosidade dos grãos, que retem a água que preenche os poros das partículas.

Atualmente muitos estudos têm sido feitos na tentativa de se modelar e de se entender a forma de absorção de água em sistemas compostos por minérios de ferro. Tais estudos se dividem em várias linhas de pesquisa, como a determinação do ângulo de contato entre a partícula e a gota de água. Isso determina o grau de hidrofobicidade de um elemento. Outra linha bastante estudada é a interferência da partição granulométrica na absorção de água no sistema como um todo. Estudos foram conduzidos levando-se em consideração o tamanho da partícula e a distribuição granulométrica do sistema de minério de ferro. Uma terceira linha de estudo segue na direção de determinar uma correlação entre o comportamento hidrofóbico ou o grau de "molhabilidade" de um sistema e sua capacidade de retenção de água de acordo com sua composição química ou, mais propriamente dizendo, a quantidade de hematita presente determina o ângulo de contato médio do sistema.

Como dito anteriormente, duas formas de adsorção de água pelo sistema são possíveis: a água contida nos poros de cada partícula e a água que fica represada entre as partículas. Em testes de laboratórios desenvolvidos na China para estudos da cinética de absorsão de água nos leitos de minérios que alimentam os processos de sinterização das industrias do aço Chinesas, a universidade de Chongqing demonstrou, através de testes em capilares, que a absorção de água em particulas grosseiras é mais rápida, e as mesmas atingem um grau de saturação elevado mais rapidamente que as partículas mais finas. Parece que a cinética da adsorção de água depende do tamanho da partícula do minério de ferro e a mesma aumenta com o aumento do tamanho da partícula [1]. Este fator parece depender de forma bem intensa do tamanho dos poros, uma vez que os mesmos podem se comportar como 
capilares para essa função. Os mesmos testes, no entanto, demonstraram que uma distribuição granulométrica maior no material tem uma velocidade de dessaturação maior do que um material com grande quantidade de partículas finas e ultra-finas.

O chamado modelo não poroso considera o efeito da água no pacote de minério de ferro, em uma ligação física em que a água funciona como ligante entre as partículas de minério de ferro, conforme mostrado na figura 1 . Se levarmos em consideração a compressibilidade do sistema e a compactação devido ao peso do leito sobre as partículas, a espessura do filme de água entre partículas é o mesmo, no entanto, o volume de líquido contido no caso de partículas desiguais é bem superior ao volume do sistema de partículas de tamanho semelhantes.

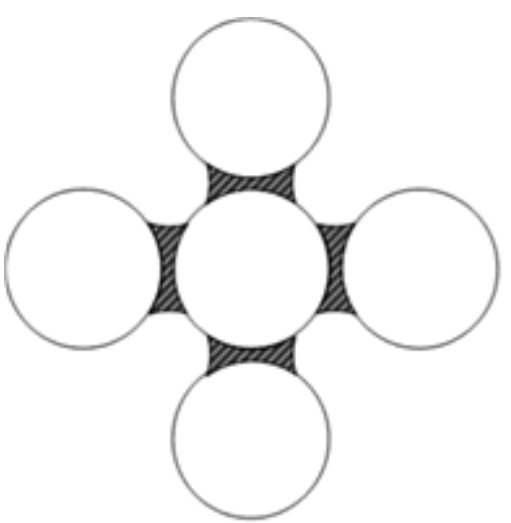

ESFERAS IGUAIS

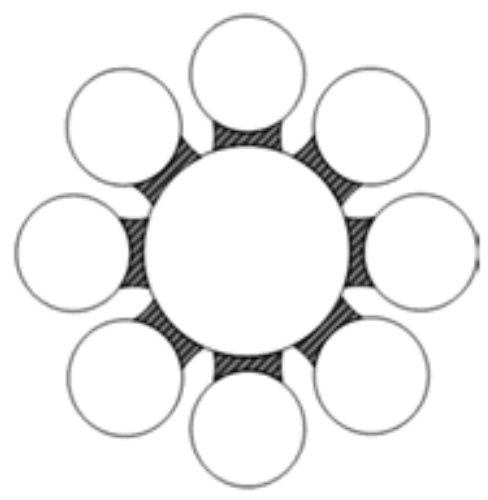

ESFERAS NÃO IGUAIS

Figura 1 - Arranjo de partículas de esferas iguais e diferentes

O volume de água no sistema composto por partículas de tamanhos diferentes é maior devido ao aumento da área superficial do conjunto à medida que temos uma distribuição granulométrica menor, isso se considerarmos a mesma espessura do filme de água. Essa relação está bem demonstrada na figura 2, em que foi considerado o volume contido no sistema para espessuras de filme de água variados $(0,025 \mathrm{~mm}, 0,035 \mathrm{~mm}, 0,045 \mathrm{~mm}, 0,085 \mathrm{~mm}$ e $0,125 \mathrm{~mm})$.

O modelo demonstra que o volume de água preso entre as partículas decresce rapidamente à medida que o raio médio das partículas aumenta [1]. Isso está parcialmente em concordância com as medições feitas com os mesmos materiais, porém as distâncias dos valores obtidos pela medição de tendência e pelos resultados previstos pelo modelo se distanciam bastante com o decrescimento do tamanho da partícula, mostrando que não existe somente um fenômeno atuando no sistema, o que o torna ainda mais complexo.

O segundo modelo mais aceito na relação água e minério de ferro é o que leva em consideração a água contida nos poros das partículas. 


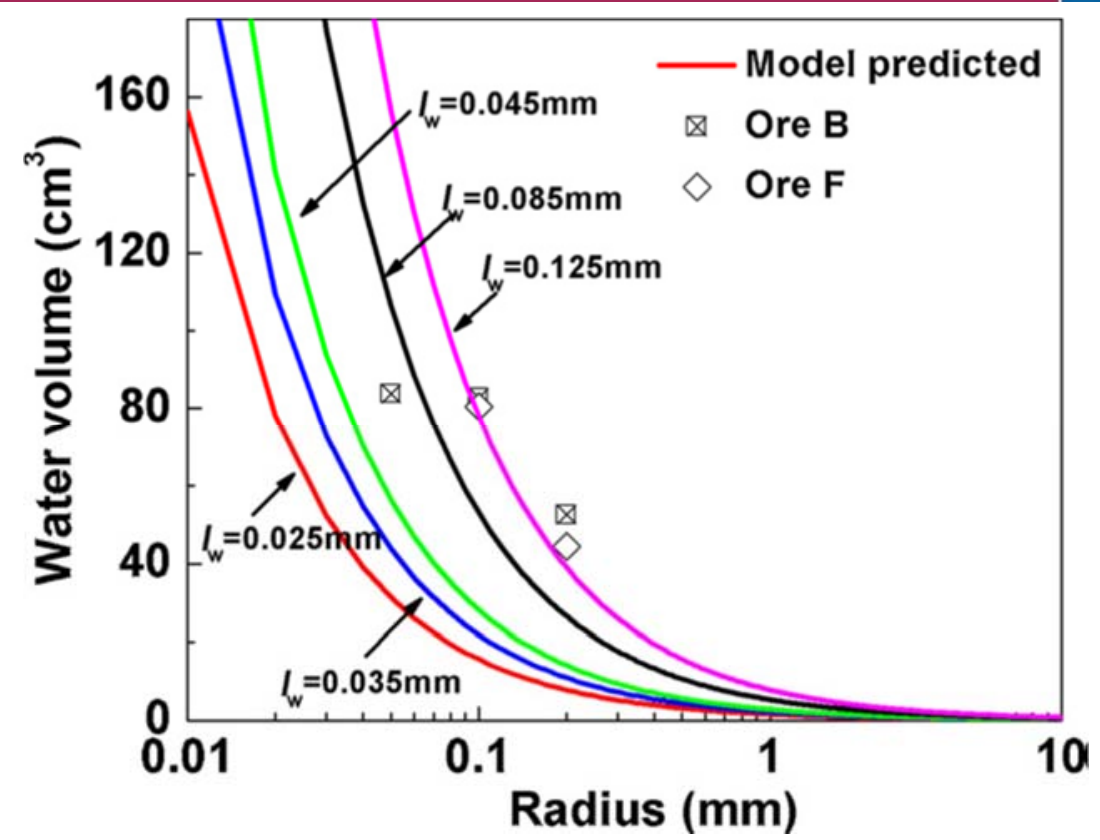

Figura 2 - Relação entre o raio da partícula e o volume de água do sistema [1].

Todos os minérios de ferro têm partículas porosas, e é nesses poros que são aprisionados uma boa parte da água contida no sistema. Existem duas possibilidades no que tange ao estudo de porosidade no minério de ferro: o poro aberto ou o poro fechado. O poro aberto é aquele em que o fluido escoa livremente da entrada para a saída, em pontos diferentes. O poro fechado é aquele em que a entrada é a mesma que a saída, e o balanço tem que ser feito levando em consideração a compressão de ar realizada pela água à medida que preenche o furo. A figura 3 apresenta esquematicamente o preenchimento de poros abertos e fechados pela água. Na figura 3(A) está demonstrado o preenchimento pela água de um poro aberto. Nessa situação a água está livre para fluir da entrada para a saída do poro. A figura 3(B) demonstra o preenchimento pela água de um poro fechado. Neste, a água só consegue penetrar até que a pressão do ar comprimido no interior do poro se iguale à pressão exercida pela água na entrada. Nas figuras $3(C)$ e 3(D), está demonstrado o efeito do preenchimento pela água em ambos os lados dos poros abertos, causando também a compressão do ar retido no interior do poro.

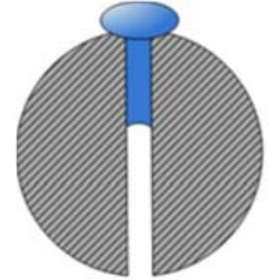

A

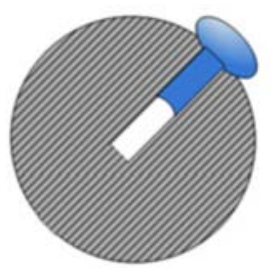

B

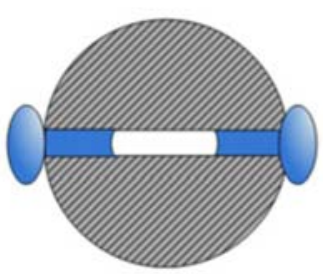

C

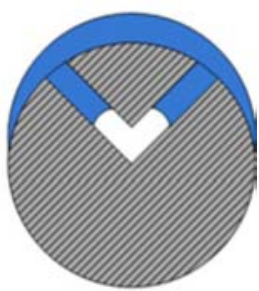

D

Figura 3 - Preenchimento dos poros de uma partícula de minério de ferro pela água. (a) preenchimento de um poro aberto; (b) preenchimento de um poro fechado; (c) e (d) preenchimento por água de um poro aberto nas duas extremidades

Quanto maior for o tamanho da partícula, a tendência natural é que o tamanho dos poros acompanhe sua distribuição. Essa relação até o momento não tem valores préestabelecidos para que se faça um modelo preciso devido à dificuldade de se avaliar e quantificar poros pequenos em cada uma das partículas. No entanto, entende-se 
que o efeito de saturação e dessaturação de um sistema tem grande influência na distribuição granulométrica e no tamanho dos poros relacionados.

Uma terceira teoria leva em consideração o efeito do ângulo de contato água/partícula para se compreender o evento de absorção em um sistema de minério de ferro. A molhabilidade de uma partícula é inferida através de seu ângulo de contato, sendo bem aceito que, ao aumentar o ângulo de contato, a aglomeração das partículas se torna mais difícil, pois diminui a força da ponte líquida que mantém as partículas atadas [3] e esse ângulo pode variar dependendo do conteúdo de hematita e Goetita presente no sistema [2].

O ângulo de contato influencia, dentre outras coisas, a quantidade de água que ficará retida na superfície e a quantidade de água que escoará para dentro dos poros. Enquanto menores ângulos de contato (melhor molhabilidade) retém grandes quantidades de água do sistema na superfície das partículas, grandes ângulos de contato fazem com que maiores quantidades de água escoem para dentro dos poros. Esse fator pode auxiliar ou prejudicar na umidade do sistema, uma vez que a água armazenada nos poros pode ou não ajudar no efeito aglomerativo.

$\mathrm{Na}$ prática, toda a água contida nos poros das partículas não exerce nenhuma influência na formação do leito de minério de ferro, pois são as gotas de água contidas na superfície que atuarão como agentes ligantes na aglomeração [2]. Isso quer dizer que, quanto menor for o ângulo de contato entre a partícula e a água, melhor será para a aglomeração e, por consequência, pior para o tratamento e tentativa de concentração ou separação a umidade natural será.

Isso não significa que a água nos poros não interfere em nada, pois uma vez submetidos a pressões externas (mesmo da coluna de minério acima), as partículas estão sujeitas a deformações de qualquer tipo e à quebra, o que pode causar a liberação desta água contida em seus poros para o ambientes, o que faria aumentar o teor de umidade no sistema e, uma vez liberada, faz-se necessário encontrar formas de se melhorar o manuseio e separação do mesmo. O fenômeno da liquefação vem sendo estudado como um tema vital, principalmente no que se refere ao manuseio e transporte de materiais [5] em países tropicais. O chamado TML (Transport Moisture Limit) é hoje foco de grandes desenvolvimentos, principalmente na indústria química. Há muito vem se perquisando a utilização de polímeros polivalentes para o auxilio na área de tratamento de minérios. Esses reagentes são normalmente derivados do acrílico, chamados poliacrilatos e, dentre várias outras utilidades, possuem uma alta capacidade de absorção de água, fazendo com que seu uso tenha estrapolado os limites dos estudos de TML a que normalmente é referenciado, para estudar sua utilização direta no tratamento de minérios à umidade natural.

Desde a utilização do amido como um absorvente, devido ao baixo custo e por se tratar de uma fonte altamente renovável, até a utilização de estruturas mais complexas como as do poliacrilatos, muitos se desenvolveram na indústria mineral. Os absorventes se encarregam de "aprisionar" a água, impedindo sua liberação e, por consequência, a liquefação do leito de minério (M. Popek, 2013). Vale lembrar que os acrilatos não reduzem a umidade do conjunto, pois não fazem "desaparecer" a água, apenas alteram suas características por uma questão de afinidade (hidrofilicidade). A distribuição granulométrica do polímero também tem grande influência no seu desempenho. 


\section{MÉTODOS E MATERIAIS}

A separação magnética a seco foi escolhida devido à presença de magnetita no minério estudado, como mostrado no capítulo anterior. Foram feitos vários testes com variações de parâmetros, tais como campo, taxa de alimentação e, em alguns casos, na utilização de rolos de campo permanente, a velocidade do rolo também foi modificada na busca de melhores resultados.

Uma vez escolhido o melhor equipamento e que se melhor adequava às condições estabelecidas ao teste, foram realizados os chamados "testes em branco", com o material completamente seco na expectativa de se obter pelo menos uma idéia de como seria o fluxograma para a concentração do material a úmido.

Foram testados os separadores magnéticos de tambores com campos permanentes de 900G, 1400G e 3500G, além de um separador magnético de rolo induzido com variações que chegaram a até $10.000 \mathrm{G}$.

Com esses equipamentos foram testados estágios Rougher, Cleaner, Scavenger e Cleaner Scavenger, na tentativa de se enriquecer o material, aumentando-se o teor de ferro e reduzindo o teor de sílica. Para se avaliar o desempenho do teste, também se levou em consideração não somente a química, mas também a recuperação em massa do circuito, de forma a se obter também a avaliação econômica como principal critério. As curvas granulométricas de ambos os materiais utilizados nos testes estão nas figuras $4(\mathrm{~A})$ e (B).

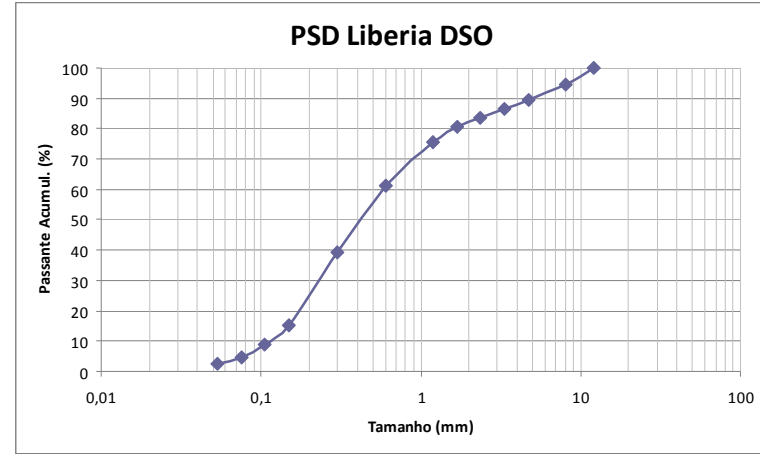

A

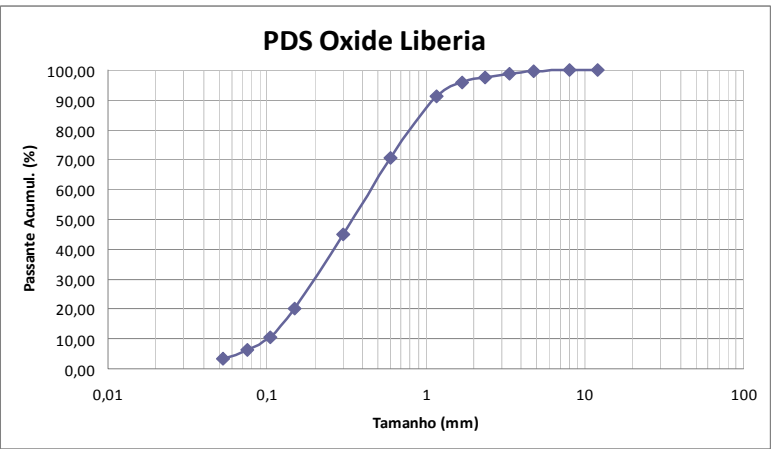

$B$

Figura 4. (a) Distribuição Granulométrica do DSO Libéria; (b) Distribuição Granulométrica do Oxide Libéria

Além do teste com o material a seco, foram testados incrementos de umidade de $6 \%$, $8 \%$ e $12 \%$ para o minério oxidado e incrementos de $6 \%$ e $8 \%$ de umidade para o DSO. O polímero foi utilizado em todos os casos de incremento de umidade na tentativa de se determinar se houve uma melhora na capacidade de separação ou se a resposta ao reagente foi negativa.

\section{RESULTADOS}

Os testes de concentração através de separação magnética para o material seco deram bons resultados de forma geral. Nos gráficos das figuras $5(A)$ e $5(B)$ estão os resultados dos testes para o DSO e o Oxide secos, sem o incremento de umidade. 


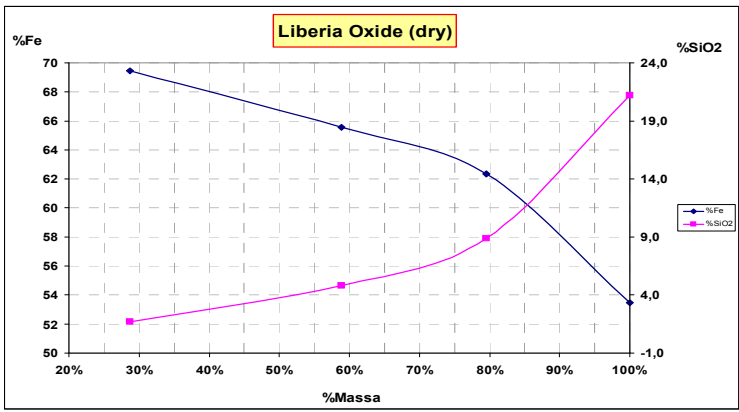

A

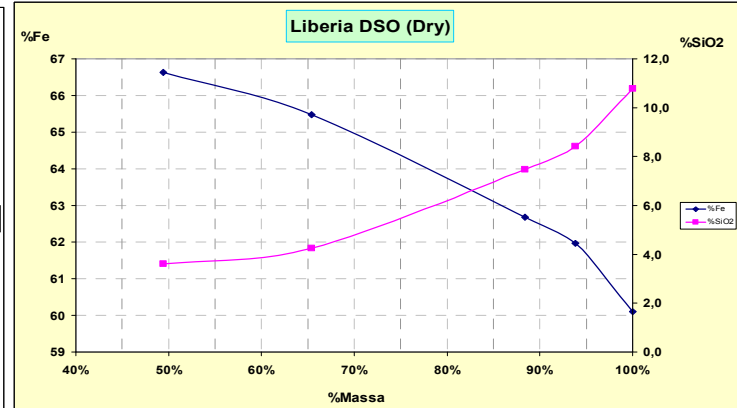

$\mathrm{B}$

Figura 5(A)(B) - Resultados de recuperação em massa pelo teor de $\mathrm{Fe}$ e $\mathrm{SiO}_{2}$

Os mesmos testes foram realizados para os incrementos de umidade até $8 \%$ para os dois materiais, mas apenas o Liberia Oxide recebeu o incremento de umidade de $12 \%$. Os resultados para os testes com o Oxide e DSO a $8 \%$ de umidade estão representados nos gráficos das figuras $6(A), 6(B)$.

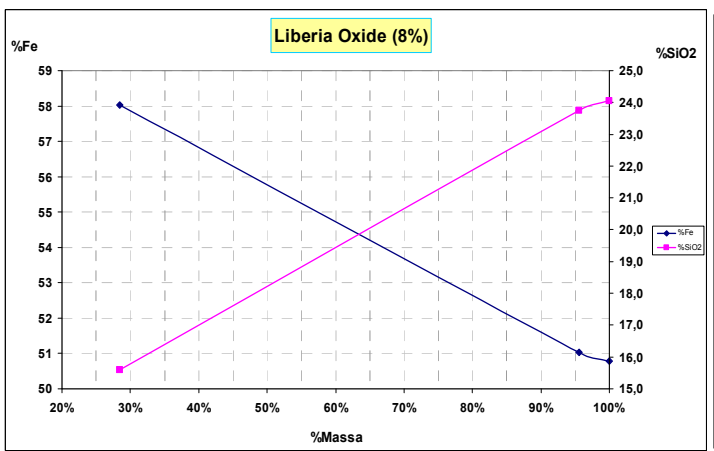

A

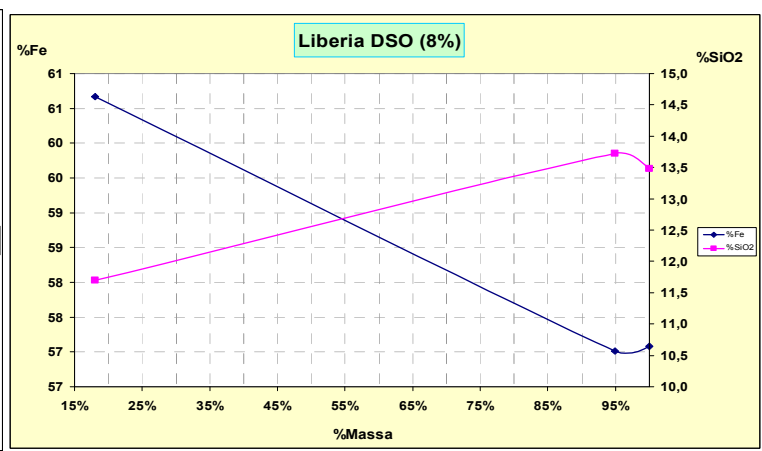

$\mathrm{B}$

Figura $6(\mathrm{~A})(\mathrm{B})$ - Resultados de RM pelo teor de $\mathrm{Fe}$ e $\mathrm{SiO}_{2}$ para $8 \%$ de umidade

Foram então realizados os testes utilizando o polímero. Os resultados são mostrados nos gráficos das figuras $7(A), 7(B)$ que descrevem o resultado da utilização do polímero para $8 \%$ de umidade para ambos os materiais e as figuras $8(A)$ e $8(B)$ para $12 \%$ de umidade no caso do Oxide.

Os testes para ambos os materiais com a umidade elevada até $6 \%$ não apresentaram resultados coerentes, muito provavelmente devido ao estabelecimento dos procedimentos para o mesmo durante a fase de testes e a possível escolha mal sucedida da rota para o mesmo. Por isso, eles não foram apresentado no trabalho corrente, mas serão alvo novamente de testes para determinação da eficiência da separação e do polímero.

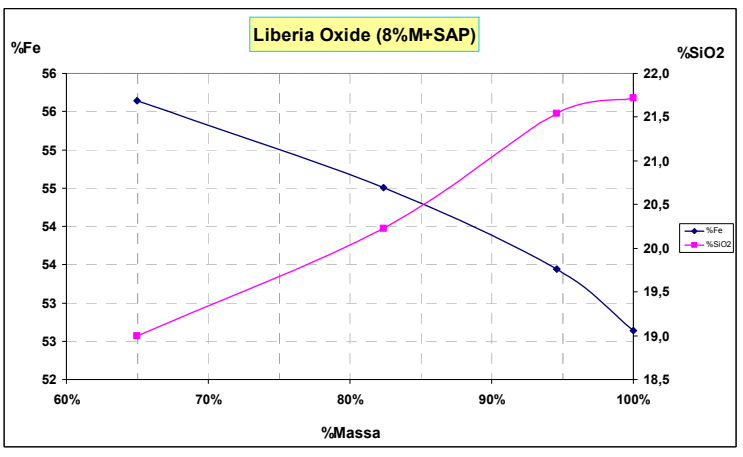

A

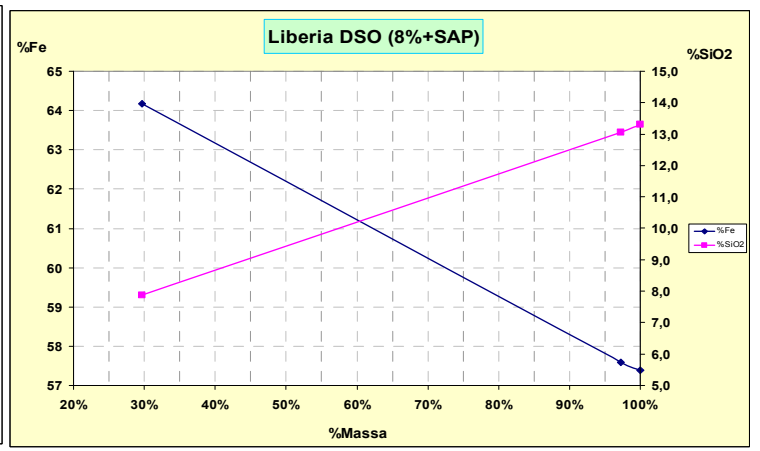

B

Figura 7(A)(B) - Resultados de RM pelo teor de $\mathrm{Fe}$ e $\mathrm{SiO}_{2}$ para $8 \%$ de umidade com a utilização do SAP (Super Absorbant Polymer) 


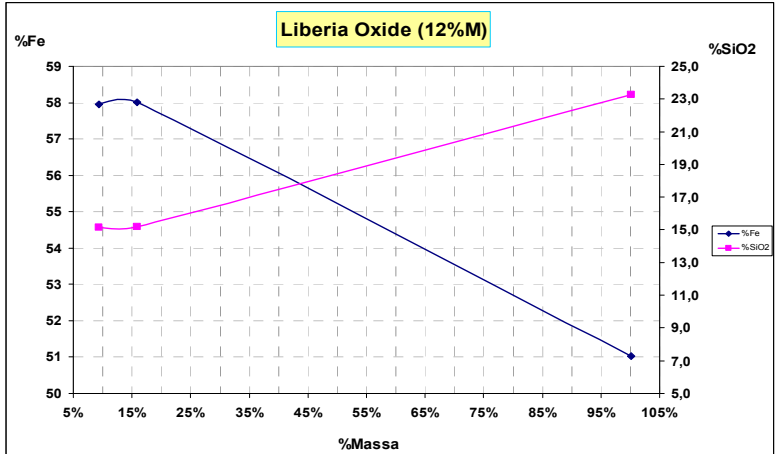

A

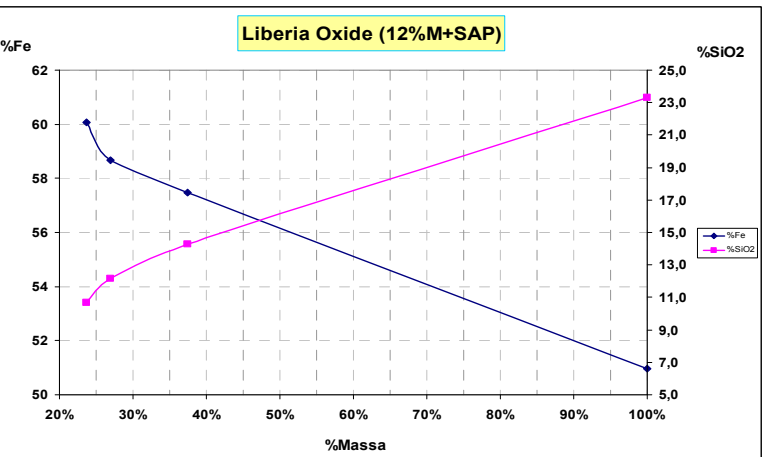

$B$

Figura 8. (a) e (b) Resultados de $\mathrm{RM}$ pelo teor de $\mathrm{Fe}$ e $\mathrm{SiO}_{2}$ para $12 \%$ de umidade com e sem a utilização do SAP para o Oxide

\section{DISCUSSÃO DOS RESULTADOS}

O processo de separação à umidade natural gera desafios tremendos, conforme demonstrado neste trabalho. O processo de concentração foi extremamente prejudicado pelo incremento da umidade nos materiais testados e, em alguns casos, tornou praticamente inútil a tentativa de se obter ganhos reais com a concentração. As tentativas de concentração por separação magnética com o material seco apresentaram resultados extremamente atrativos, como mostram as tabelas $1 \mathrm{e} 2$. A tabela 1 mostra os resultados para o Oxide da Libéria e a tabela 2 mostra o resultado para o DSO.

Tabela 1 - Resultados para a separação magnética do Oxide.

\begin{tabular}{|c|c|c|c|c|c|}
\hline \multicolumn{7}{|c|}{ Liberia Oxide: Concentrado Sep. Magnética } \\
\hline Umidade & $\%$ Massa & $\% \mathrm{Fe}$ & $\% \mathrm{SiO} 2$ & $\% \mathrm{Fe} \mathrm{Rec}$ & $\%$ SiO2 Dist. \\
\hline Dry @ 65\%Fe & $58,9 \%$ & 65,56 & 4,81 & $72,2 \%$ & $13,4 \%$ \\
\hline Dry @ 62\%Fe & $79,5 \%$ & 62,36 & 8,88 & $92,7 \%$ & $33,3 \%$ \\
\hline $6 \% \mathrm{M}$ & $75,5 \%$ & 58,25 & 14,85 & $78,0 \%$ & $66,5 \%$ \\
\hline $8 \% \mathrm{M}$ & $28,4 \%$ & 58,03 & 15,60 & $32,5 \%$ & $18,4 \%$ \\
\hline $8 \% \mathrm{M}+\mathrm{SAP}$ & $65,0 \%$ & 55,64 & 19,00 & $68,7 \%$ & $56,9 \%$ \\
\hline $12 \% \mathrm{M}$ & $9,4 \%$ & 57,96 & 15,15 & $10,6 \%$ & $6,1 \%$ \\
\hline $12 \% \mathrm{M}+\mathrm{SAP}$ & $23,7 \%$ & 60,08 & 10,68 & $28,0 \%$ & $10,9 \%$ \\
\hline \hline Alimentação & $100 \%$ & 54,25 & 20,60 & $100 \%$ & $100 \%$ \\
\hline \hline
\end{tabular}

Tabela 2 - Resultados para a separação magnética do DSO.

\begin{tabular}{|c|c|c|c|c|c|}
\hline \multicolumn{5}{|c|}{ Liberia DSO: Concentrado Sep. Magnética } \\
\hline Umidade & $\%$ Massa & $\% \mathrm{Fe}$ & $\% \mathrm{SiO} 2$ & $\% \mathrm{Fe} \mathrm{Rec}$ & $\%$ SiO2 Dist. \\
\hline Dry @ 65\%Fe & $65,4 \%$ & 65,48 & 4,26 & $71,3 \%$ & $25,8 \%$ \\
\hline Dry @ 62\%Fe & $88,4 \%$ & 62,67 & 7,48 & $92,2 \%$ & $61,3 \%$ \\
\hline $6 \% \mathrm{M}$ & $31,8 \%$ & 60,05 & 11,85 & $33,2 \%$ & $29,6 \%$ \\
\hline $8 \% \mathrm{M}$ & $18,0 \%$ & 60,67 & 11,70 & $19,1 \%$ & $15,6 \%$ \\
\hline $8 \% \mathrm{M}+\mathrm{SAP}$ & $29,7 \%$ & 64,17 & 7,87 & $33,2 \%$ & $17,6 \%$ \\
\hline \hline Alimentação & $100 \%$ & 57,76 & 12,87 & $100 \%$ & $100 \%$ \\
\hline \hline
\end{tabular}

A utilização dos polímeros demonstrou uma boa contribuição para o aumento da capacidade de separação de ambos os materiais. Em alguns casos, como o 8\%+SAP apresentou concentrados bastante atrativos, no entanto, a recuperação em massa faz 
com que ele seja novamente avaliado nas futuras rotas e alternativas a serem testadas.

\section{CONCLUSÕES}

O processo de separação magnética à umidade natural pode ser uma alternativa viável para materiais até então considerados marginais. Há que se avaliar com bastante critério a questão econômica, uma vez que a incorporação de reagentes auxiliares implica também a inserção de novos custos a processos altamente afetados por fatores de mercado.

O polímero demonstrou aumentar a capacidade de separação dos circuitos e para o material em que foi testado, porém a recuperação mássica em tais processos caiu drasticamente, sendo necessária a incorporação de etapas de limpezas e recuperação do material, aumentando assim a complexidade da rota.

As rotas são simples e de fácil implementação, sem que haja grandes desembolsos em termos de CaPEx e mantendo o OpEx em patameres bastante competitivos. A operação com a separação é simples e a adição de polímeros não apresenta grandes desafios.

\section{REFERÊNCIAS}

1 Xuewei Lv; Chenguang Bai; Guibao Qiu; Meilong Hu. Kinetics of water absorption by the bed of iron ore particles during granulation - School of Materials Science and Engineering, Chongqing University, 2011.

2 S.M. Iveson, S. Holtb, S. Biggsb. Advancing contact angle of iron ores as a function of their hematite and goethite content: implications for pelletizing and sintering - University of Newcastle, Australia, 2004.

3 Maraglou, A., "Fluidiser and granulation," PhD thesis - University of Birmingham, UK, 1987.

4 Michael C. Munro, Abbas Mohajerani. Determination of the transportable moisture

5 limit of iron ore fines for the prevention of liquefaction in bulk carriers School of Civil, Environmental and Chemical Engineering, RMIT University, Melbourne, Victoria, Australia, 2014.

6 M. Popek. The influence of organic polymer on parameters determining ability to liquefaction of mineral concentrates - Gdynia Maritime University, Gdynia, Poland, 2013. 